\title{
UMA CANTIGA DE AMIGO MODERNA: ANÁLISE DE “A ANUNCIAÇÃO”, DE VINICIUS DE MORAES
}

\section{A modern cantiga de amigo: analysis of "A anunciação" by Vinicius de} Moraes

Jonathan Lucas MOREIRA LEITE 25

UFPB

\author{
moreira_jon@hotmail.com
}

\section{Luciana Eleonora de Freitas Calado DEPLAGNE 26 \\ UFPB \\ lucianaeleonora@yahoo.com.br}

RESUMO: O presente artigo tem como objetivo analisar as marcas da literatura trovadoresca na poesia de Vinicius de Moraes, focalizando o diálogo entre a cantiga de amor medieval e os poemas do autor. Para tal, analisaremos o poema "A anunciação" presente no livro Nova antologia (2003). Nosso estudo utiliza como arcabouço teórico as contribuições trazidas à baila pelos medievalistas Spina (1956) e Dronke (1978), o poeta e ensaísta Octavio Paz (1994); além dos trabalhos sobre Neotrovadorismo das professoras Maria Maleval (2002) e Almeida Cunha (2008). O trabalho desenvolverá uma breve análise sobre as marcas trovadorescas nos textos do autor escolhido e focalizará o poema citado em comparação com a cantiga de amigo dos trovadores.

Palavras-chave: Vinicius de Moraes. Trovadorismo. Neotrovadorismo.

\footnotetext{
${ }^{25}$ Mestrando em Letras pelo PPGL - UFPB.

${ }^{26}$ Professora Adjunto I do Departamento de Letras Clássicas e Vernáculas da UFPB, doutora pela sandwich na Université Blaise-Pascal, em Clermont-Ferrand, na França.

Revista TextoPoético | ISSN: 1808-5385 | Vol. 21 (2o sem-2016) - p. 125.
} 
ABSTRACT: This article aims to analyze the marks of troubadour literature in Vinicius de Moraes poetry, focusing on the dialogue between the medieval cantiga de amor and the author's poems. To do this, we will analyze the poem "A Anunciação" from the book Nova Antologia (2003). Our study uses as a theoretical framework the contributions by the medievalists Spina (1956) and Dronke (1978), the poet and essayist Octavio Paz (1994); and the works about Neo-troubadourism by the professors Maria Maleval (2002) and Almeida Cunha (2008). This study will develop a brief analysis of the troubadour marks in the text of the chosen author and examine more closely the poem quoted in comparison with the cantiga de amigo of the troubadours.

Keywords: Vinicius de Moraes; Troubadour; Neo-troubadourism.

\section{Introdução}

O carioca Vinicius de Moraes viveu de 1913 a 1980 e foi, antes de tudo, um artista consciente e inquieto. Tornou-se bacharel em Letras pelo Colégio Santo Inácio em 1929 e formou-se em Direito 1933. Desde muito jovem foi influenciado por dois mundos que, para ele, nunca foram opostos: o erudito e o popular. Seu pai, Clodoaldo Pereira da Silva Moraes, era um ex-professor de Francês e escrevia sonetos muito influenciados pela estética parnasiana, nunca publicados em livro. Sua mãe, Lídia Cruz de Moraes, tocava piano, assim como boa parte da família materna de Vinicius. O poeta foi durante muitos anos diplomata, profissão que o levou a morar em diversas cidades como Roma, Los Angeles e Londres. Em 1969, desligado do seu cargo, passou a dedicar-se exclusivamente à poesia e à canção popular.

O autor publicou doze livros de poesia e deixou uma considerável produção que não foi publicada em vida. Além da poesia, Vinicius escreveu crônicas, reunidas nos livros Para viver um grande amor (1962) e Para uma menina com uma flor (1966), e críticas sobre cinema. O poeta teve uma exitosa passagem pelo teatro com o musical "Orfeu da Conceição", que ganhou adaptação para o cinema e foi

Revista TextoPoético | ISSN: 1808-5385 | Vol. 21 (2o sem-2016) - p. 126. 
premiada com a Palma de ouro, o Cannes e o Oscar de melhor filme estrangeiro do ano de 1959.

Poeta elogiado por pares como Manuel Bandeira e João Cabral de Melo Neto, o apelido de "poetinha" só pode ser entendido a partir do carinho que o diminutivo pode expressar e, nunca, como querem alguns, tomando Vinicius como um poeta menor. $\mathrm{O}$ autor foi fundamental para a bossa nova e por conseguinte para a música brasileira que é produzida até hoje. São suas as letras de "Garota de Ipanema"; "Chega de saudade" e "A felicidade", versos que o eternizaram como um dos compositores de maior importância na história de nossa música.

Acreditamos que uma das possibilidades de leitura da poesia de Vinicius de Moraes é interpretá-la a partir do Neotrovadorismo. Se observarmos o trabalho do poeta, em linhas gerais, podemos notar a existência de dois momentos bastante distintos em sua obra, entendemos que ambos podem ser lidos como ressonâncias trovadorescas na poesia do autor. A primeira característica, presente principalmente em seus primeiros livros, Caminho para a distância (1933) e Forma e exegese (1935) - ganhador do prêmio nacional de literatura -, diz respeito a uma busca por Deus, pelo transcendental, pela metafísica a partir da religiosidade cristã, sem com isso restringirse a ela. Há uma ligação entre o poeta e Deus, seja a busca do eu-lírico pelo divino, seja a comunhão entre o sagrado e o humano, transformando o ato de escrever em algo que transcende a razão. Sobre a mística no período medieval, afirma a pesquisadora Mariani (2009):

Mística é então, nesse contexto, discurso sobre a relação com Deus daquele que faz um percurso que implica o envolvimento num trabalho de despojamento de si, para deixar-se transformar pelo totalmente Outro que, em sua grandeza e liberdade, é absolutamente transcendente,

Revista TextoPoético | ISSN: 1808-5385 | Vol. 21 (2o sem-2016) - p. 127. 
impossivel para o entendimento e o querer humanos (MARIANI, 2009, p. 371).

Podemos observar tais considerações nos versos do poema " $\mathrm{O}$ poeta" (2008, p. 33): "O poeta é o destinado do sofrimento [...] E a sua alma é uma parcela do infinito distante / $\mathrm{O}$ infinito que ninguém sonda e ninguém compreende [...] o poeta não teme a morte" ou no poema "Os malditos (A aparição do poeta)" (2011, p. 83): "E que somos belos como deuses mas somos trágicos / Viemos de longe... Quem sabe no sono de Deus tenhamos aparecido como espectros". Há, nestes dois primeiros livros, um Vinicius menos conhecido, melancólico e afeito às questões existenciais. 'O que é o poeta' é um assunto presente nos dois poemas citados; o eu-lírico relaciona, constantemente, o poeta, a inspiração poética ou o fazer poético com a transcendência da mística ligação com Deus. Esta face do poeta não chega a desaparecer logo em seguida, porém tais poemas tornam-se cada vez mais espaçados na sua obra.

A segunda característica é a mais conhecida do poeta, o amor. $\mathrm{O}$ elogio à sua amada, o sofrimento amoroso, a paixão irrefreável. Em alguns poemas o amor aparece de forma pura, platônica e em outros o amor é vinculado ao desejo sexual. Podemos observar esta exaltação ao amor nos versos da canção "Canto de Xangô": "Amar é sofrer / Mas amar é morrer de dor [...] Me faça sofrer / Ah me faça morrer / Mas me faça morrer de amar". Entendemos que uma possibilidade de analisar esses poemas de Vinicius de Moraes seja a partir do diálogo com o amor cortês dos trovadores.

Vinicius de Moraes é comumente ligado à figura do trovador, muito possivelmente por sua, já referida, ligação tanto com a canção quanto com a poesia. Além disso, um dos temas mais abordados pelo autor é a devoção e a exaltação à mulher amada, tema

Revista TextoPoético | ISSN: 1808-5385 | Vol. 21 (2o sem-2016) - p. 128. 
reconhecidamente ligado aos trovadores. Apesar dessa associação comum de Vinicius como um trovador, ao consultarmos o banco da Capes $^{27}$, não encontramos, dentre as dissertações e teses, nenhum estudo que tinha como objetivo analisar o trovadorismo presente em sua obra.

A proposta deste artigo é de analisar a relação entre o poema "A anunciação" e a cantiga de amigo trovadoresca. Antes de proceder à análise, propomos, no tópico a seguir, uma breve reiteração de alguns importantes conceitos sobre o trovadorismo e suas atualizações na arte moderna e contemporânea.

\section{Neotrovadorismo: tradição e modernidade}

A história da arte é feita de rompimentos e reaproximações com estéticas anteriores; rompe-se com algumas, dialoga-se com outras. Temos o marcado exemplo do Romantismo que se desligou da tradição Árcade enquanto recorreu, muitas vezes, à estética medieval; o Romantismo, por sua vez, foi posto em xeque pelos Realistas. Uma das maiores forças criadoras da arte é exatamente essa intertextualidade, esse jogo de atração e repulsão entre as diversas formas de pensá-la e produzi-la.

No caso particular do trovadorismo, podemos observar diversos diálogos com essa estética através dos séculos que lhe sucederam. Como exemplo, citamos o medievalista Segismundo Spina (2006, p. 19) sobre Camões: “A própria gentil senhora dos sonetos camonianos não é mais que uma sobrevivência da pseudonímia poética dos trovadores, que, na observância à mesura, criaram o retrato ideal da

${ }^{27}$ Endereço eletrônico: http://www.capes.gov.br/servicos/banco-de-teses

Revista TextoPoético | ISSN: 1808-5385 | Vol. 21 (2o sem-2016) - p. 129. 
criatura amada". Posteriormente, Fernando Pessoa publica um poema intitulado "D. Dinis". Segue o poema:

\section{DINIS}

Na noite escreve um seu Cantar de Amigo

O plantador de naus a haver,

E ouve um silêncio múrmuro consigo:

É o rumor dos pinhais que, como um trigo

De Império, ondulam sem se poder ver.

Arroio, esse cantar, jovem e puro,

Busca o oceano por achar;

E a fala dos pinhais, marulho obscuro,

É o som presente desse mar futuro,

É a voz da terra ansiando pelo mar.

(PESSOA, 1936, 1972, p. 73)

Lemos, então, nos dois mais aclamados poetas portugueses, seus diálogos com o trovadorismo. Sobre o poema-homenagem ao rei-poeta D. Dinis, afirma a medievalista Maleval, em breve análise:

O poema remete-nos para a época do rei-trovador, acentuando-lhe os presságios do futuro Império ultramarino em belíssimas imagens (dos pinhais), dotadas de cor sugestiva de riqueza ("como um trigo de Império"), movimento ("ondulam") e som ("rumor", "fala", "marulho"), que se confundem com o seu cantar de "arroio", na busca do oceano desconhecido. (MALEVAL. 2002. P 10)

Segundo Maleval, Manuel Rodrigues Lapa, em 1933, denominou esse diálogo com a cultura medieval como Neotrovadorismo, termo que desde então vem sendo utilizado nos estudos referentes às ressonâncias da cultura medieval. A professora descreve essa estética da seguinte forma:

Tal movimento neotrovadoresco - se é que podemos assim caracterizá-lo, uma vez que sem manifestos ou outro tipo de doutrinamento - não fora meramente saudosista do esplendor

Revista TextoPoético | ISSN: 1808-5385 | Vol. 21 (2o sem-2016) - p. 130. 
passado. Embora heterogêneo, pode ser definido como, na síntese de Xosé Manuel Enríquez, uma "recriación do universo poético medieval (ambiente e recursos formais: paralelismo, refrán, leixa-pren...) co espírito do século $X X "$ (MALEVAL, 2002. p 21)

Não há um manifesto do Neotrovadorismo, como houve nas vanguardas europeias. Não existiu ou existe uma organização articulada entre os autores para construir uma arte que resgatasse o medievo; por isso a ressalva da autora ao utilizar "movimento" para discorrer sobre o Neotrovadorismo. O que podemos afirmar com certeza é que diversos artistas utilizam nas suas obras um constante diálogo com os conteúdos e/ou com as formas medievais.

Entendemos que o Neotrovadorismo não é apenas um resgate da cultura medieval no sentido de repeti-la, imitá-la; é, antes, uma recriação, uma transfiguração dos elementos medievais. Concordamos com Maleval ${ }^{28}$ quando ela afirma: "Nele [Neotrovadorismo] se uniriam as audácias metafóricas da poesia moderna com as velhas formas de expressão lírica, tornando-o um fenômeno também original".

Focalizando a cultura moderna e contemporânea brasileira, é muito difícil determinar quem foi o primeiro autor Neotrovadoresco nacional. Porém, Maleval (2002) afirma: "embora não possamos determinar com precisão quem teria sido o seu primeiro realizador, citamos, como pioneiros, Onestaldo de Pennafort, Martins Fontes, Paulo Bonfim, Augusto Meyer".

Tanto nas chamadas artes populares, quanto nas eruditas, diversos autores brasileiros utilizam-se do diálogo com o trovadorismo para

${ }^{28}$ MALEVAL, Maria do Amparo Tavares. Peregrinação e poesia. Rio de Janeiro: Editora Ágora da Ilha, 1999. P 83.

Revista TextoPoético | ISSN: 1808-5385 | Vol. 21 (2o sem-2016) - p. 131. 
construir suas obras. Dentre as obras que podem ser consideradas Neotrovadorescas, devemos destacar a incidência desse fenômeno no nordeste brasileiro. A literatura de cordel, os cantadores e o movimento Armorial são amplamente influenciados pela cultura medieval. Poetas e prosadores como Cego Aderaldo, Oliveira de Panelas e Ariano Suassuna representam muito fortemente essa herança.

As interseções entre a cultura medieval e o nordeste brasileiro são inegáveis; basta lembrar as pelejas dos cantadores; a oralidade e musicalidade indissociáveis na poesia popular com o uso comum das redondilhas; a dimensão mítico-fantástica das narrativas orais e escritas; os romanceiros, o eco das novelas de cavalaria nas histórias, cantadas ou não, que, muitas vezes, trazem os cangaceiros como protagonistas.

No caso específico do movimento Armorial, que surgiu nos anos 1970 capitaneado pelo paraibano Ariano Suassuna, observamos um resgate à tradição nordestina a partir do diálogo com a cultura ibérica medieval. É importante frisar que o movimento Armorial busca a valorização da cultura popular nordestina. Logo o diálogo com o mundo medieval é um meio de enaltecer a sabida ligação do Nordeste com essa tradição. (Barbalho 2004)

No âmbito da canção popular brasileira, além da própria execução cantada de um texto, fato que remete, imediatamente, aos trovadores; não é raro observamos recriações trovadorescas nas obras de compositores como Caetano Veloso, Gonzaguinha e Gilberto Gil. Temos como exemplo o estudo realizado pela professora Calado (2000), no qual Chico Buarque foi descrito como um "moderno trovador". A pesquisadora identificou nas canções do autor diversas marcas do medievo, categorizando as canções a partir dos gêneros

Revista TextoPoético | ISSN: 1808-5385 | Vol. 21 (2o sem-2016) - p. 132. 
poéticos trovadorescos, como as cantigas de amor ("A Rita", "Tanta saudade") e as cantigas de amigo ("Atrás da porta", "Olhos nos olhos").

Dentro do universo da poesia, destacamos a importante pesquisa que Maleval (2002) desenvolveu sobre a relação do Neotrovadorismo e o modernismo brasileiro. $\mathrm{O}$ trabalho conta com uma antologia dos poetas que, segundo a autora, "praticaram as suas incursões poéticas no medievo". Entre eles estão Cecília Meireles, Manuel Bandeira e Guilherme de Almeida.

Dentre os poetas brasileiros contemporâneos, Stella Leonardos representa um exemplo bastante interessante de como o diálogo com o trovadorismo pode ser feito de forma integral e completamente consciente, utilizando-se dos temas, das formas e até, algumas vezes, da língua arcaica. Podemos observar essa assertiva no poema que segue:

\section{DO CANCIONEIRO DA DESAJUDA}

FLOR do ramo

flor do ramo:

ven cantiga.

"Ai flores, ai flores do verde pino, se sabedes novas do meu amigo!

Ai Deus, e u é?"

En que seja Dona Flor

non quero cantar d' amor.

Nen cantar de maldizer.

Sou d' agosto, vivo a gosto,

a contragosto vos amo

e o gosto meu é morrer.

Revista TextoPoético | ISSN: 1808-5385 | Vol. 21 (2o sem-2016) - p. 133. 
"Ai flores, ai flores do verde ramo, se sabedes novas do meu amado!

Ai deus, e u é?"

Flor sem ramo.

Do enramado

sen cantiga.

(LEONARDOS, 1974, p. 76)

Stella Leonardos dialoga, nesse poema, com os versos da cantiga de amigo (CBN 568, CV 171) do rei poeta D. Dinis, "Ai flores, ai flores do verde ramo". O diálogo acontece tanto na epígrafe trazida por Leonardos, com a indicação do primeiro verso da cantiga e de sua autoria, quanto na inserção de duas estrofes da cantiga medieval, apresentadas no poema entre aspas e em estrofes alternadas, dandolhes destaque da espacialidade na folha. É interessante observarmos a inovação em diálogo com a tradição. Percebe-se que a poeta utiliza-se do português arcaico e da redondilha maior, porém desde o título "Do cancioneiro da desajuda" a autora recria o sentido tradicional da cantiga. No poema de Leonardos, o eu-lírico não se envaidece do sofrimento que o amor causa, muito pelo contrário, afirma: "a contragosto vos amo / e o gosto meu é morrer".

O descrito acima aplica-se a outros poetas modernos brasileiros. Ao dialogar com o medievo não perdem a marca moderna de suas obras. Sobre a poesia moderna brasileira Maleval afirma:

No Brasil, mesmo os líderes do Modernismo - movimento que propugnava uma arte nacionalista, ligada à sociedade tecnológica, caracterizada pela liberdade de ideias e de formas, pela ruptura com o passado europocentrista souberam aproveitar a herança das nossas origens líricas, como o próprio Mário de Andrade, que se dizia "um tupi tangendo um alaúde" (Andrade, 1987, p. 83). Por exemplo,

Revista TextoPoético | ISSN: 1808-5385 | Vol. 21 (2o sem-2016) - p. 134. 
em alguns dos seus poemas de Lira paulistana, é visível o diálogo com Martin Codax, jogral galego do século XIII, que imortalizou para todo o sempre as "ondas do mar de Vigo" em letra e música (Maleval, 2002, p. 28-34).

Pensando que o movimento modernista execrava toda a arte que se embebesse do estilo lusitano - incluindo, talvez erroneamente, o aclamado Machado de Assis -, as incursões dos poetas modernistas em uma tradição literária galego-portuguesa podem parecer, inicialmente, contraditórias com os preceitos do movimento. Maleval nos esclarece, contudo, acerca desse estranhamento:

O Trovadorismo medievo, diga-se de passagem, não fizera parte da tradição literária portuguesa incorporada pelos brasileiros e combatida pelos modernistas. Isto porque, após séculos de desconhecimento, os Cancioneiros galaicoportugueses apenas em fins do século XIX e inícios do XX foram publicados, a partir dos manuscritos medievos e tardomedievos; o que tornou possivel o advento do Neotrovadorismo. (Maleval, 2002, p. 28-34).

Entre os autores modernos brasileiros que podem ser lidos através dos olhos do Neotrovadorismo está o poeta focalizado na nossa análise, Vinicius de Moraes. Apesar de o autor não ter sido incluído na seleção, já referida nesse trabalho, realizada por Maleval, é possível observar, tanto nas poesias cantadas, quanto nas poesias dos livros, diversas recorrências às temáticas ligadas ao medievo, como explicitamos no decorrer deste trabalho.

A pesquisadora Sílvia Marisa Almeida Cunha (2008) cita a tipologia organizada pela medievalista Teresa López sobre os neotrovadores; para López é possível categorizar o neotrovadorismo em três tipos. São eles:

1) aquel que reproduz mimeticamente os modelos da poesia medieval;

Revista TextoPoético | ISSN: 1808-5385 | Vol. 21 (2o sem-2016) - p. 135. 
2) aquel que recria a atmosfera, ambiente, símbolos, estrutura e procedimentos de tipo paralelístico, que obrigan a ler estes textos en confronto coa lírica medieval;

3) aquel que utiliza fórmulas e estilemas medievais, ben polo seu carácter falsamente popular elou exótico para construir imaxes vanguardistas (simbolistas, criacionistas e mesmo surrealistas) ben polo carácter lúdico dentro das correntes neopopularistas de vanguarda (LÓPEZ apud CUNHA 2008, p. 30-31)

Almeida Cunha (2008) aponta para uma problemática na tipologia feita por Teresa López: há uma dificuldade em distinguir claramente as duas últimas categorias, tendo em vista que elas podem coexistir na mesma composição. Além disso, a autora discorre sobre as composições "cuja forma e musicalidade nos remetem, de imediato, para os códigos fónico-rítmicos explorados pelos trovadores medievais, sem que haja, ao nível temático, qualquer aproximação" (CUNHA, 2008, p 10), que não são contempladas pela tipologia referida. A autora sugere, então, uma revisão da tipologia proposta por Teresa López:

1) composições que evidenciam uma reprodução mimética, onde, aliando os temas à forma, encontramos uma reprodução quase perfeita das cantigas trovadorescas;

2) composições onde se evidencia a referência ao universo trovadoresco, através do reavivamento dos seus símbolos e personagens, versos ou expressões, que podem variar entre uma ou mais referências (incidindo a sua manifestação no plano temático ou vocabular);

3) composições que manifestam uma aproximação formal muito evidente, evocando, de imediato, no leitor a sonoridade da lírica medieval, estatuindo, porém, um efeito de estranhamento anacrónico, uma vez que, ao nível temático, se distanciam das referidas cantigas. (CUNHA, 2008, p 10)

Revista TextoPoético | ISSN: 1808-5385 | Vol. 21 (2o sem-2016) - p. 136. 
Pensando nessa tipologia, entendemos que Vinicius de Moraes se enquadra no segundo grupo. Os textos do poeta dialogam com elementos medievais como o amor cortês, sem reproduzir, via de regra, as estruturas formais das cantigas trovadorescas e sem utilizarse da língua arcaica; diferentemente do que acontece, por exemplo, com alguns poetas brasileiros, como é o caso de Stella Leonardos, acima referida. $\mathrm{O}$ autor dialoga em sua poesia com o universo medieval, sem com isso restringir os sentidos do poema apenas para esse diálogo. Um poema de Vinicius de Moraes em que o eu-lírico dialogue com a vassalagem amorosa, com a exaltação à amada, pode ser analisado como uma obra neotrovadoresca, mas não terá seu entendimento restrito aos leitores que dispõem de conhecimento acerca das cantigas provençais.

Para esclarecermos uma das incursões Neotrovadorescas na poesia de Vinicius de Moraes, analisaremos a seguir o poema "A anunciação".

\section{A anunciação: o cantar feminino de Vinícius de Moraes}

O poema "A anunciação", presente na Nova antologia poética (2003), é um dos diversos textos de Vinicius de Moraes em que é possível encontrar as ressonâncias da poesia trovadoresca em sua obra. Neste poema, em particular, analisaremos suas similitudes com a cantiga de amigo trovadoresca. Vamos ao poema:

Revista TextoPoético | ISSN: 1808-5385 | Vol. 21 (2o sem-2016) - p. 137. 


\section{A anunciação}

1 Virgem! filha minha

2 De onde vens assim

3 Tão suja de terra

4 Cheirando a jasmim

5 A saia com mancha

6 De flor carmesim

$7 \mathrm{E}$ os brincos da orelha

8 Fazendo tlintlin?

9 Minha mãe querida

10 Venho do jardim

11 Onde a olhar o céu

12 Fui, adormeci.

13 Quando despertei

14 Cheirava a jasmim

15 Que um anjo esfolhava

16 Por cima de mim...

No poema acima fica visível o diálogo entre duas vozes femininas, o que nos remete, imediatamente, à cantiga de amigo, "gênero poético cultivado pelos trovadores, cuja principal característica é a expressão dos sentimentos através de um eu-lírico feminino" (CALADO, 2000, p 24). Os conceitos desse gênero poético serão desenvolvidos, mais detalhadamente, durante a análise do poema. No texto de Vinicius de Moraes é evidente um diálogo entre a donzela e sua mãe. Sobre os diálogos presentes nessas cantigas afirma Calado:

Num universo estritamente feminino, longe inclusive da figura paterna, a Cantiga de Amigo se desenvolve com o desabafo amoroso de uma donzela, ora a uma amiga ou irmã; ora à sua mãe, que nem sempre é conivente com ela; ora ao próprio namorado ou amante, numa espécie de debate amoroso; algumas vezes, o desabafo é dirigido às ondas do mar ou ao rio. (CALADO, 2000, p 25)

Revista TextoPoético | ISSN: 1808-5385 | Vol. 21 (2o sem-2016) - p. 138. 
O diálogo entre a donzela e uma confidente é bastante comum entre as cantigas de amigo, como afirma Dronke (1978, p. 111): "Es especialmente en las canciones que la muchacha dirige a su confidente, su madre, donde puede verse hasta qué punto de complicación porían llegar sus sentimientos".

No plano formal podemos atentar para a regularidade dos versos, ritmo, métrica e rima. É notável sua cadência quando o poema é lido em voz alta. Essa musicalidade é resultante da alternância regular entre as sílabas fortes e fracas. Não menos responsável por isso é a rima presente em todos os versos pares. O poema é formado, desde o título, por versos de cinco sílabas, o que nos remete à poesia provençal, como afirma Goldstein (2006, p. 33): "O verso de cinco sílabas, ou redondilha menor já era empregado na Idade Média pelos poetas portugueses nas cantigas de amor e de amigo".

A semelhança formal com o cancioneiro popular pode ser percebida se compararmos o poema com algumas marcas desse gênero, como a presença da rima soante apenas em versos alternados; estrutura binária do verso, onde cada dupla de versos formam, sintaticamente, uma só frase (VAN WOENSEL, VIANA, 1998, p. 126).

Uma característica muito presente no trovadorismo é a ligação com a religiosidade. No poema analisado existe um discurso religioso que atravessa o texto. O título "A anunciação" remete, inevitavelmente, à visita do anjo Gabriel à Maria, avisando-a de sua gravidez. No primeiro verso, a mãe diz "Virgem!", que pode ser analisado, em sua pluralidade de sentido, como uma expressão exclamativa ou como uma alusão à Maria, o que muito se ajusta à poesia provençal, pois muitas vezes a exaltação da mulher fora

Revista TextoPoético | ISSN: 1808-5385 | Vol. 21 (2o sem-2016) - p. 139. 
canalizada para o símbolo religioso da virgem. Sobre isso desenvolve Spina:

A musa trovadoresca passa a ser dirigida pelo extra oficial da Igreja, derivando então para o lirismo contemplativo da Virgem; as condições favoreciam essa derivação, pois o serviço cavalheiresco, humilde e genuflexo, que prestava o vassalo, o home-lige, diante de sua dama, tinha o seu correspondente religioso na genuflexão dos fiéis diante da virgem. (SPINA, 1956. $p$ 23)

As referências à religiosidade cristã aparecem, por exemplo, com o surgimento da figura do anjo no $15^{\circ}$ verso. Porém nesse poema os termos referentes à religiosidade não têm a mesma função daqueles frequentemente encontrados nas cantigas de amor, com uma forma de exaltação da virgem Maria. Podemos pensar aqui que o termo "Virgem" funciona, antes, como intertexto para antecipar ao leitor questões relativas à virgindade da dama. Tais insinuações vão se intensificando ao longo do poema através de imagens que sugerem uma possível defloração da donzela.

Há no poema uma forte presença da natureza, em vários versos espalham-se palavras como terra, jasmim, flor, jardim e céu. Na poesia provençal, não apenas nas cantigas de amigo, como também nas cantigas de amor, é muito presente a correspondência entre a dama e a natureza, seja ao seu estado emocional, seja à caracterização da sua interlocutora, seja do próprio eu-lírico.

O poema estrutura-se em duas partes: os primeiros oito versos constituem a fala da mãe e os versos seguintes correspondem à resposta da filha. A mãe, preocupada, pergunta onde estivera a filha que chega agora "tão suja de terra / cheirando a jasmim / A saia com mancha / de flor carmesim". Pensando na forma que a mãe descreve o estado da filha, o jasmim é, segundo o dicionário Aurélio (2000), "Flor

Revista TextoPoético | ISSN: 1808-5385 | Vol. 21 (2o sem-2016) - p. 140. 
alva, perfumadíssima"; e o carmesim ${ }^{29}$, "Cor carmesim, associada pela sua intensidade à cor do pecado", como nos aponta a passagem bíblica no livro de Isaias 1:18: "Vinde, pois, e arrazoemos - diz o Senhor. Ainda que vossos pecados sejam como a escarlata, eles se tornarão brancos como a neve; ainda que sejam vermelhos como o carmesim, se tornarão como a lã.”. Então, a filha volta à presença da mãe, cheirando a uma flor esbranquiçada, toda suja de terra e com uma mancha vermelha no vestido. Estabelece-se, então, a dúvida sobre a desfloração da virgem.

Na segunda metade do poema, a filha responde à mãe onde estivera durante esse tempo: "Venho do jardim / Onde a olhar o céu / Fui, adormeci. / Quando despertei / Cheirava a jasmim / Que um anjo esfolhava / Por cima de mim...”. A amiga relata à mãe que, quando acordou, um anjo esfolhava jasmim por cima dela. A flor esbranquiçada, utilizada tanto pela mãe quanto pela filha, alude, provavelmente, ao sêmen. Aqui o anjo da anunciação não apenas comunica a gravidez da virgem, como no texto bíblico, mas uma metáfora possível é a de que o anjo seja o protagonista da possível desfloração da donzela.

Outro fato que merece atenção nesse contexto da religiosidade é o lugar em que a "donzela" afirma ter estado com o anjo. No décimo verso, a filha declara que vem do "jardim"; dentro da construção do poema podemos, perfeitamente, analisar esse jardim como uma referência ao Éden, sendo assim, ao pecado original. Essa interpretação vai ao encontro da desfloração da virgem. A importância do jardim, ou pomar, não fica apenas no intertexto religioso. $\mathrm{Na}$ literatura cortês, o jardim é o espaço das delícias, de sensualidade, do

${ }^{29}$ Ver: http://www.bibliaonline.com.br/acf/is/

Revista TextoPoético | ISSN: 1808-5385 | Vol. 21 (2o sem-2016) - p. 141. 
encontro dos amantes, local fechado, secreto. Sobre a representação desse segundo jardim, afirma Ronchetti:

Na descrição poética, o jardim é, então, um espaço fechado em que se entra por uma porta, circundado por um muro que separa o que está dentro do que está fora, a realidade exterior e a interior: o espaço do jardim é um fresco alegórico de um lugar sem tempo, lugar da eterna primavera, sempre cheio de frutos e flores que não conhecem a caducidade. (RONCHETTI, 2009, p 269)

O jardim ocupa, no poema, uma função de visível polissemia: a insinuação da desfloração da donzela dialoga com o intertexto religioso que se forma desde o título, remetendo, imediatamente, à mística cristã da Virgem mãe de Deus, que fora assim anunciada por um anjo.

Como foi possível observar durante a análise, o poema pode ser lido como um texto Neotrovadoresco, o que fica claro tanto do ponto de vista formal quanto temático. Dentre as diversas fontes que o poeta Vinicius de Moraes nutriu sua obra poética uma delas foi, sem dúvidas, a poesia provençal.

\section{Considerações finais}

Vinicius de Moraes tem uma respeitável obra na poesia e na canção popular. O poeta tem sua obra marcada pela mudança, pela diversidade. José Castello, na biografia Vinicius de Moraes: O poeta da paixão (1994, p. 20), afirma que Vinicius foi rejuvenescendo com os anos. O jovem conservador e direitista passou a ser um ateu de esquerda e terminou a vida confortável com o misticismo dos Orixás. A sua obra, sem dúvidas, reflete estas mudanças ideológicas.

Revista TextoPoético | ISSN: 1808-5385 | Vol. 21 (2o sem-2016) - p. 142. 
Um homem que viveu e produziu entre o popular e o erudito, que entre o atrito desses dois mundos fez sua obra poético-musical. $\mathrm{Na}$ obra de Vinicius existem poemas que dialogam com a metafísica, outros com as representações amorosas, alguns de desejo sexual avassalador e ainda aqueles em que a crítica social ganha força no lirismo do poeta.

Entendemos que uma face do camaleônico Vinicius de Moraes é a do trovador. Além de o autor fazer poesias para serem cantadas, seus versos promovem um diálogo possível com a lírica trovadoresca. $\mathrm{O}$ amor integral dos trovadores encontra eco no Amor Total de Vinicius. A devoção do eu-lírico à amada, o elogio àquela mulher acima de todas as outras, a entrega incondicional ao amor como forma de vida, tal qual o código dos trovadores.

\section{Referências}

BARBALHO, A. Estado, mídia e identidade: políticas de cultura no Nordeste contemporâneo. In: ALCEU - v. 4 -n. 8 -p. 156-167 -jan./jun. 2004.

CALADO, L. E. de F. Chico Buarque: um moderno trovador. João Pessoa: Ideia, 2000.

CARPEAUX, O. M. História da Literatura Ocidental. Rio de Janeiro: Cruzeiro, 1961.

CASTELLO, J. Vinicius de Moraes: o poeta da paixão, uma biografia. São Paulo: Companhia das Letras, 1994.

DRONKE, P. La lírica en la Edad Media. Barcelona: Seix Barral, 1978.

GIL, D. V. A poesia esparsa de Vinicius de Moraes. Rio de Janeiro: UFRJ/ FL, 2009.

Revista TextoPoético | ISSN: 1808-5385 | Vol. 21 (2o sem-2016) - p. 143. 
GOLDSTEIN, N. Versos, sons e ritmos. São Paulo: Ática, 2007. (Série Princípios, v. 6)

HOMEM, W. ; DE LA ROSA, B. História das canções. São Paulo: Leya, 2013.

LEONARDO, S. Amanhecência. Rio de Janeiro: Aguilar; Brasília: INL, 1974.

MALEVAL, M. do A. T. Peregrinação e poesia. Rio de Janeiro: Ágora da Ilha, 1999.

. Poesia medieval no Brasil. Rio de Janeiro: Ágora da Ilha, 2002.

MARIANI, C. B. Mística e Teologia: desafios contemporâneos e contribuições. Atualidade Teológica: Revista do Dpto. de Teologia da PUCRio, Rio de Janeiro, ano XIII, n. 33, set. a dez. 2009. Disponível em: $<$ http://www.maxwell.lambda.ele.puc-

rio.br/rev teologia.php?strSecao=input0 $>$. Acesso em: 25 jun. 2014.

MONGELLI, L. M.; VIEIRA, Y. A estética medieval. Direção de Massaud Moisés. Cotia, SP: Editora Íbis, 2003.

MORAES, V. de. Forma e exegese / Ariana, a mulher. São Paulo: Companhia das Letras, 2011.

. Livro de sonetos. São Paulo: Companhia das Letras, 2009.

. Nova antologia poética. Org. Antonio Cicero e Eucanaã Ferraz. São Paulo: Companhia das Letras, 2003.

. Novas poemas (II). São Paulo: Companhia das Letras, 2012.

. Novos poemas / Cinco elegias. São Paulo: Companhia das Letras 2012.

. O caminho para a distância. São Paulo: Companhia das Letras, 2008.

.Poemas, sonetos e baladas e Pátria minha. São Paulo: Companhia das Letras, 2008.

Revista TextoPoético | ISSN: 1808-5385 | Vol. 21 (2o sem-2016) - p. 144. 
OSAKABE, H. Textos medievais e portugueses e suas fontes. São Paulo: Humanitas, 1999.

PAZ, O. A dupla chama. Tradução de Wladir Dupont. São Paulo: Siciliano, 1994.

POUND, E. ABC da literatura. 11. ed. Tradução de Augusto de Campos. São Paulo: Cultrix, 2006.

RONCHETTI, C. Do jardim místico ao jardim profano: Para uma leitura dos jardins medievais portugueses. Revista de história da arte, n. ${ }^{\circ} 7$-FCSH-UNL, 2009.

SPINA, S. Apresentação da Lírica Trovadoresca. Rio de Janeiro: Livraria Acadêmica, 1956.

. Era Medieval. Rio de Janeiro: DIFEL, 2006.

VAN WOENSEL, M.; VIANA, C. Poesia medieval: ontem e hoje. João Pessoa: Editora da UFPB. 1998.

VILHENA, M. da C. A duas 'cantigas medievais' de Bandeira. Separata da Revista do Instituto de Estudos Brasileiros, 17: 51-66. São Paulo: USP, 1975.

Aprovado em 17 de março de 2016.

Revista TextoPoético | ISSN: 1808-5385 | Vol. 21 (2o sem-2016) - p. 145. 